\title{
An experimental study of horizontal well steam flooding in shallow and thin extra-heavy oil reservoir
}

\section{Proceeding}

Horizontal well steam flooding has strongly been proved to be a valuable and remarkable recovery technique for developing heavy oil reservoirs. However steam channeling and serious steam override has been the two major difficulties of developing shallow and thin extra-heavy oil reservoirs. Therefore it became necessary to indepth understanding of characteristic of steam channeling and steam override during horizontal well steam flooding. Based on similarity criterion, a scaled physical model was fabricated, containing four horizontal wells and representing one fourth of an inverted nine-spot steam flooding pattern. A series of physical simulation experiments were carried out with steam flooding after different types of integral cyclic steam stimulations. Temperature distributions in the model reservoir, overburden, and substratum were measured every 10 seconds. Production performance can be exactly recorded. The spatial temperature distribution of the whole model can be obtained by using the Kriging interpolation method. Photoshop software was introduced to quantitatively describe every temperature zone.

The phenomena of steam channeling and steam override were observed obviously during steam flooding after cyclic steam stimulations. The results show that characteristic of steam channeling and steam override in different types of integral cyclic steam stimulations are very distinct. During steam flooding after integral cyclic steam stimulations of two wells in the same row, the following three steam channeling mode will appear in sequence: 'A-A' steam channeling, 'B-B' steam channeling and 'B-A' steam channeling. However, during steam flooding after integral cyclic steam stimulations of two wells in the same column, the sequence of steam channeling will change as follows: 'B-A', 'A-A' and 'B-B' steam channeling. And the first cyclic steam stimulation presents worse steam override than the second in late period.
Volume 2 Issue 2 - 2017

\author{
Lei Wang, Huiqing Liu, Zhanxi Pang, Xueqi \\ Cen \\ Department of Petroleum Engineering, China University of \\ Petroleum, China
}

Correspondence: Lei Wang, Department of Petroleum Engineering, China University of Petroleum, China, Email jzwangleil0508@I63.com

Received: December 16, 2016 | Published: February 22, 2017

The effect of steam injection velocity of steam flooding on the sequence of steam channeling has also been investigated. When the velocity is low, it is easy to present the ' $\mathrm{B}-\mathrm{A}$ ' steam channeling; but the velocity is high, the 'A-A' steam channeling will firstly appear. The steam override becomes worse as the velocity increases.

Some novel understanding of steam channeling and steam override in shallow and thin extra-heavy oil reservoir is observed through a series of physical simulation experiments. At various types of integral cyclic steam stimulations and viscosity conditions steam channeling and steam override present different characteristics and changing processes. Thus, these basis understandings can provide the guidance for the design of horizontal well steam stimulation and steam flooding in shallow and thin extra-heavy oil reservoir effectively.

\section{Acknowledgements}

None.

\section{Conflict of interest}

The author declares no conflict of interest. 